\title{
Is Spirituality Effective in Addiction Recovery and Prevention?
}

\section{ABDU'L-MISSAGH GHADIRIAN and SHADI SALEHIAN}

\section{Abstract}

Affecting millions, the rise of substance abuse, ${ }^{1}$ particularly opioids, has become a global health crisis, the leading cause of death and disability worldwide. Despite extensive scientific advances in understanding the complex biopsychosocial components of this phenomenon, there is no relief in sight. Yet, research studies during the past twenty years reveal an important role for spirituality and religion in prevention and recovery. The primary purpose of this article is to explore this role, examine various theories that have emerged about the positive influence of spirituality, and consider how an effective approach to prevention and treatment might be realized.

\section{Résumé}

Touchant des millions de personnes, l'augmentation du taux d'abus de substances, en particulier d'opiö̈des, est devenue une crise sanitaire mondiale et la première cause de décès et d'invalidité

1 The terms "addiction" and "substance abuse" will be used interchangeably in this article. Moreover, the word "drugs" refers, for the most part, to illicit drugs. dans le monde. Malgré les progrès scientifiques considérables réalisés quant à la compréhension des composantes biopsychosociales complexes de ce phénomène, il n'y a pas de répit en vue. Pourtant, des recherches menées au cours des vingt dernières années révèlent que la spiritualité et la religion jouent un rôle important dans la prévention et le rétablissement. Le but premier de cet article est d'explorer ce rôle, d'examiner diverses théories qui ont émergé au sujet de l'influence positive de la spiritualité et de considérer comment une approche efficace de prévention et de traitement pourrait être développée.

\section{Resumen}

Afectando a millones, el aumento del abuso de sustancias, particularmente opioides, se ha convertido en una crisis global de salud, la causa principal de muerte y discapacidad mundial. A pesar de extensos avances científicos en la comprensión de los componentes biopsicosociales complejos de este fenómeno, no hay alivio a la vista. Sin embargo, estudios investigativos durante los últimos 20 años revelan un rol importante para la espiritualidad y la religión en la prevención y la recuperación. El propósito primario de este artículo es explorar este rol, examinar varias teorías que han emergido sobre la influencia positiva de la espiritualidad, y considerar cómo un enfoque efectivo a la prevención y el tratamiento puede ser realizado.

In 2014, the New York Times reported that a thirteen-year-old child had overdosed on heroin and, as a result, he was left paralyzed, confined to a wheelchair and unable to function independently for the rest of his life (Seelye). At a very young age, any 
dream he might have had of a productive future had been dashed. Similar situations have been the plight of thousands of people, especially youth, in North America in recent years, calling to mind these words of Bahá'u'lláh: "O Son of Spirit! I created thee rich, why dost thou bring thyself down to poverty? Noble I made thee, wherewith dost thou abase thyself?" (Arabic Hidden Words, no. 22).

The scourge of drug addiction, affecting all strata of society irrespective of socio-economic, cultural, or religious background, afflicts and touches populations in every corner of the globe. The staggering statistics related to the scope and pervasiveness of this disease highlight the urgent need both to understand its nature and to undertake a collective effort to tackle this serious public health crisis. The present article proposes to explore the central role that spirituality plays in human wellbeing and the significant effect it can have on treatment and recovery from addictions.

Addiction to psychoactive drugs is a complex biopsychosocial disease, defined by the World Health Organization (WHO) as "the harmful and hazardous use of psychoactive substances, including alcohol and illicit drugs" ("Substance Abuse"). It is a chronic disease with relapsing episodes that cause compulsive drug-seeking behavior and the use of certain substances in spite of their harmful consequences to the addicted individuals and those around them ("Prescription Drug Abuse”). Behavioral symptoms of addiction vary depending on the type of substance used and the intensity of the condition. While a full description of these symptoms is beyond the scope of this article, psychoactive drugs can overpower the human mind and the brain's normal activities and can disrupt individual judgment, emotion, and behavior. In the long run, the need to repeatedly use these drugs may become a constant preoccupation-what we term an addiction.

Unlike diseases with primarily biological components contributing to their development-such as diabetes, pneumonia, or rheumatoid arthritisdrug addiction is strongly characterized by the involvement of social and psychological factors in its evolution and may, therefore, be responsive to methods that include spirituality-in addition to conventional treatmentin the prevention of its development and in the process of recovery.

\section{Prevalence of Substance Abuse}

It is estimated that in 2016,275 million people $(5.6 \%$ of the world's population aged sixteen to sixty-four years) used drugs at least once, according to the United Nations Office on Drugs and Crime (UNODC) ("World Drug Report” 7). Furthermore, thirty-one million in this group suffer from a drug use disorder requiring treatment. The UNODC also states, "Cannabis was the most commonly used drug in 2016, with 192 million people using it at least once in the past year. The global number of cannabis users continues 
to rise and appears to have increased by roughly 16 per cent in the decade ending 2016, which is in line with the increase in the world population" (11).

The UNODC's report indicates that opioids, including heroin, continue to be among the most harmful drugs. In addition to the possibility of both fatal and non-fatal overdoses, users also risk developing infectious diseases—such as HIV and Hepatitis C-and other medical and mental illnesses. When illicit drugs such as cocaine, amphetamines, and cannabis are consumed in combination with one another, users place themselves in great peril. Drug overdoses kill more people than gun homicides, car crashes, and suicides combined, making drug abuse the leading cause of death for Americans under age fifty ("Drug Overdoses"). The toll in the last ten years has surpassed the number of deaths in the Vietnam War and is accelerating yearly.

Although the tragic opioid epidemic in North America has attracted significant public attention, a dangerous rise in the use of alcohol is also of great concern. In the United States, for example, research reveals that in recent decades there has been an increase in the use of alcohol among the elderly, women, and minorities. In older individuals, alcohol abuse can result in higher levels of alcohol in their blood, with disturbing consequences, such as impairment of judgement, loss of coordination, falls, and other sorts of accidents.

According to the WHO, alcohol and tobacco are considered psychoactive substances that can cause dependency ("Substance Abuse"). Nevertheless, they are not treated as "controlled substances" and are still widely accepted as harmless (or even desirable) by society when consumed in moderation. The number of college-aged women drinking is approaching that of men-another cause of concern because women are more prone to experiencing blackouts when blood alcohol levels rise too high. In addition, excessive alcohol consumption puts them at greater risk of breast cancer (Schuckit, qtd. in Blake 23).

The notion that the experience of pain should be eliminated or reduced to extremely low levels - a trend in medical treatment that quickly gained ground in the 1990s-has resulted in the rise in opiate use that has now reached epidemic proportions in the United States and Canada. The U.S. Centers for Disease Control reported that in 2016 alone more than 64,000 Americans died of drug overdose, the equivalent of 142 deaths daily, or one death every nineteen minutes ("Provisional Counts"). Of these, seventy-eight percent are caused by fentanyl, or other prescription opioids. In fact, it is estimated that one in seven Americans has abused prescription drugs.

Another important impact of drug addiction is the cost to society. For example, in the United States, the annual cost of addiction (tobacco, alcohol, and illicit drugs) in terms of lost work productivity, healthcare, and crime, is estimated to be over $\$ 740$ billion, a 
figure greater than the GDP of many developing countries. Illicit drugs and prescription opioids are estimated to burden healthcare with a combined $\$ 350$ billion of otherwise needless expense ("Prescription Drug Abuse").

This cost is astronomical in comparison with how the same money could be spent were it applied to primary healthcare, public health, preventive education, and other endeavors that could improve the lives of the general public. Such calculations of economic impact, however, do not and cannot ever reflect the extent of human suffering and the toll taken on individual lives, families, and communities shattered by substance abuse.

\section{Risk and Predisposing Factors}

Because there are many predisposing factors that lead to substance abuse, there is no magic bullet for prevention of addiction, and hence no single approach will be sufficient for its treatment. Risk factors may be biological, psychological, or cultural. Genetic and biological predisposing factors have been extensively studied, in particular among alcoholics. A family history of alcoholism or other addictions combined with a genetic predisposition may make some individuals susceptible to substance abuse. Patients with mental illness are more at risk for substance abuse disorders, a fact that further complicates treatment for this group of individuals. As mental disorders such as depression and other psychiatric afflictions affect twenty-five percent of the world's population ("Mental Disorders"), the added risk of psychoactive drug abuse is of immense concern.

The National Institute on Drug Abuse lists the risk and protective factors in drug abuse as follows:

\section{Protective factors:}

- strong and positive family

bonds;

- parental monitoring of chil-

dren's activities and peers;

- clear rules of conduct that are

consistently enforced within the family;

- involvement of parents in the

lives of their children;

- success in school performance;

- strong bonds with institutions, such as school and religious organizations; and

- adoption of conventional norms about drug use.

Risk factors:

- chaotic home environments, particularly in which parents abuse substances or suffer from mental illnesses;

- ineffective parenting, especially with children with difficult temperaments or conduct disorders; - lack of parent-child attachments and nurturing; - inappropriately shy or aggressive behavior in the classroom; - failure in school performance; - poor social coping skills; 
- affiliations with peers displaying deviant behaviors; and - perceptions of approval of drug-using behaviors in family, work, school, peer, and community environments.

Family conflict and the general breakdown of family life remove a major protective factor in social, mental, and spiritual wellbeing and also pose significant risk factors for addictive behavior. Individuals who have a history of traumatic experiences-especially women who have been subjected to abuse and soldiers who have returned from a traumatizing war zone, thereby experiencing post-traumatic stress disorder (PTSD) and depression-are also at risk for developing substance abuse disorders.

It is also well-known that people tend to mirror behavior of their friends and colleagues, especially during teenage and college years when they are most susceptible to social pressures and may be more inclined to adopt adverse behavior in order to be accepted. Consequently, peer pressure has been shown to be a strong predictor of experimentation with drug use, and early exposure to habit-forming drugs can have long-lasting effects; therefore, for many people, experimentation in teenage years results in devastating consequences in later life (Ghadirian, Alcohol and Drug Abuse 79). The increased availability of illegal drugs combined with freedom to indulge in pleasure-seeking behavior has further contributed to the current extent of this tragedy.
As mentioned earlier, the current trend in pain management has magnified an existing danger because a history of prolonged exposure to opioids after medical treatment can also be a major risk factor in the development of addiction. This danger is now at the center of the greatest public health challenge affecting the North American continent.

\section{The Opioid CRISIS}

In a materialistic society, happiness is perceived as a commodity that can be purchased in a store, kept in a bottle, consumed in pills, and served at parties. This type of "happiness" can stimulate the brain and excite the emotions, but it can also lead to addiction and cause accidents, even death (Ghadirian, Alcohol and Drugs $85)$.

However, the search for happiness is not the only reason behind thousands of people's use of psychoactive drugs. Individuals experiencing pain and discomfort are seldom offered treatment beyond the use of pain-killers, especially prescription opioids, such as morphine, heroin, and codeine. These opioids include drugs such as OxyContin and Vicodin that are mostly prescribed for the treatment of moderate to severe pain. They act by attaching to specific proteins called opioid receptors, which are found on nerve cells in the brain, spinal cord, gastrointestinal tract, and other organs in the body. When these drugs attach to their receptors, 
they reduce the perception of pain and can produce a sense of well-being ... (Volkow 5).

Endorphins, which are morphinelike hormones produced by the central nervous system and the pituitary gland, also have pain-reducing and uplifting effects (Bergland). However, " $[\mathrm{w}]$ ith repeated administration of opioid drugs, the production of endogenous opioids [i.e., endorphins] is inhibited, which accounts in part for the discomfort that ensues when the drugs are discontinued (i.e., withdrawal)" (Volkow 5).

There is no easy or definitive answer as to how to prevent and remedy the pervasive spread of substance use in society. Despite significant progress in harm reduction, treatment, and crisis intervention, as well as in primary prevention to counteract opioid abuse, the crisis has not abated. According to the American Academy of Neurology, more than 100,000 people have died in the United States since more liberal opioid prescription began-from 1999 to 2010 (Gagnon 12). It is estimated that more than ninety Americans die every day from opioid overdoses (Levin), in spite of the increased availability and use of Naloxone, which is quite effective in reversing the effects of opioid overdose. One reason for this increase is that sixty percent of patients don't receive medication-assisted treatment, largely due to the stigma attached to such treatment (qtd. in Levin). Presently, researchers are working on a vaccine to prevent opioid drugs from attaching to nerve cells. However, is it beneficial to the body, mind, and spirit of human beings to use one chemical to counteract another, or might there be other, better ways to remedy this pervasive crisis of epidemic proportions?

\section{Spirituality and Substance Abuse}

The choice of modality for treating substance abuse is influenced by theories about its nature, including medical, moral, and social models. The medical model suggests that drug abuse and addiction is a disease requiring diagnosis followed by treatment according to modern medicine-which includes pharmacological, dietary, psychological, and rehabilitative interventions. This model is very popular, especially among medical clinicians and researchers. The moral model of addiction proposes that addictive behavior is a moral defect-that is, the individual intentionally chooses to use drugs and is therefore responsible for the consequences of this choice. It also holds that the addict should be able to cease consumption of psychoactive drugs with the help of counselling and other therapeutic means such as medication, counselling, and so on. The social learning or behavioral model is based on the notion that addiction is a learned behavior that is reinforced by the social environment. As such, an addictive behavior can also be unlearned (UNODC 45). These three theories regarding the dependency of mind and body on addictive substances take biological, moral, and 
psychosocial perspectives. However, we posit that there is also a spiritual dimension to addiction that merits exploration.

There is no single, universally agreed-upon definition of spirituality, partly because the human spirit is not a tangible object that can be examined or measured. Some call spirituality a process: "The process of developing one's spiritual capacities is called spiritual growth or simply spirituality" (Hatcher 935-36). Others see it as a science: "Spirituality is a complete science that entails a comprehensive study of the intrinsic nature of the soul and its relationship both to the external world and to Universal Consciousness" (Tigunait 5). Many people associate spirituality with religion, while others do not. Hill and Pargament propose that "spirituality can be understood as a search for the sacred, a process through which people seek to discover, hold on to and, when necessary, transform whatever they hold sacred in their lives" (64-65). Psychiatrist Harold G. Koenig, a leading researcher of spirituality, religion, and medicine, holds that "the concept of spirituality is found in all cultures and societies. It is expressed in an individual's search for ultimate meaning through participation in religion and/ or belief in God" (Medicine, Religion and Health 13). In this discussion of the relevance of spirituality to addiction, we will employ the terms "spirituality" and "religiosity" in the context of transcendence, that which is beyond the realm of physical reality.
In his review of research studies, Koenig reports that religion/spirituality has a positive effect on hope in seventy-three percent of the population and on optimism in eighty-one percent ("Religion, Spirituality, and Health: A Review and Update" 20). Of course, consumption of illicit drugs gives an illusion that life is pleasant because psychoactive substances can numb and distort one's perception of reality. The desire to seek illicit drugs may be reduced by spiritual beliefs, which, if authentic and based on reality, provide individuals with an intrinsic moral framework that enables them to recognize the actual purpose and meaning in life. According to one study, religion and spirituality are among "the most important cultural factors that give structure and meaning to human values, behaviour and experiences" (Mueller et al. 1225). The authors further state, "Religious and spiritual practices (e.g. meditation, prayer, and worship) engender positive emotions such as hope, love, [and] contentment" (1229).

Unfortunately, the significance of spirituality and religious values in preventing, treating, and recovering from drug abuse has long been ignored or underestimated. A notable exception is Alcoholics Anonymous (AA). Its Twelve-Step program contains spiritual principles that enable people to overcome their obsession with drink. AA's success during the past eighty years in empowering addicts to take charge of their lives has finally ignited a great interest among those in the 
health sciences. Indeed, even though the mechanism of spiritual empowerment remains an enigma, research studies on AA's Twelve-Step Program have confirmed its efficacy (Kissman and Maurer).

There has been, in fact, an increasing amount of literature in recent decades suggesting that spirituality and religiosity have positive effects on health and wellbeing. Of approximately 1,200 such studies published up to the year 2000, seventy percent were on mental health and thirty percent on physical health; many more studies have been produced since then (Koenig, Medicine, Religion and Health 22). For example, Jarusiewiez explored the relationship between personal spirituality and success in addiction recovery. She found that not only did a greater proportion of recovering individuals report having faith beliefs and attaching importance to spirituality than those who showed continuing relapse, but also the converse- that relapsing individuals manifested lower levels of spirituality than those in recovery states.

Researchers White and Laudet also found that there is an inverse relationship between spirituality and drug abuse and addiction-individuals with higher degrees of spirituality or religiosity are less likely to consume alcohol and illicit drugs. Their study suggests that " $[\mathrm{t}]$ here is growing evidence that spirituality can serve as an antidote for substance use disorders" (57). These researchers also conducted a study of 354 previously heroin- and cocaine-dependent people in New York City, which proposed that spirituality can reduce the risk of relapse by acting as a protective buffer against the stress of initial recovery (Laudet and White). Moreover, higher spirituality at the beginning of the study predicted sustained recovery at the follow-up interview.

Neff and MacMaster explored the spiritual transformation process and its implications for behavioral change in individuals with substance abuse, specifically in the context of the AA Twelve-Step program. They suggested that, for such addicted individuals, engaging in a search for meaning in life is fundamental to the process of recovery. They also explored "possible spiritual change mechanisms underlying behavioral change in substance abuse treatment, with a particular focus upon 'faith-based' treatment" (47). Among the elements of transformation examined in their study were the effect of role modeling and peer influence in facilitating transformation in belief and behavior; how empathy, forgiveness, and acceptance contribute to individuals' engagement in efforts to transform their substance abuse behavior into positive attitude and action; what necessary skills reinforce such a change; and how social support in a community setting can assist in the process. In brief, they found that spiritual insights gained can lead to behavioral change, discontinuing drug use, and ultimately recovery.

In the Project MATCH Research Group study, one of the largest 
randomized trials of spiritually based treatment, researchers compared Twelve-Step Facilitation Therapy (TSF) with cognitive behavioral skill training and motivational enhancement therapy. Individuals assigned to the TSF group fared at least as well as those assigned to the other two groups, especially in measures of complete abstinence (984).

However, in all these treatment groups, both AA and religiosity or spirituality were shown to have modest positive correlation with the outcomes.

\section{The Role of Religion}

Throughout the history of mankind, spirituality and religion have been closely integrated with healing the sick and suffering. Religious beliefs have served as a powerful means of coping with disease and health crises. In particular, prayer has played an important role in alleviating suffering. Indeed, in the past it was thought that having faith was an essential ingredient in the pursuit of whole-person care within the doctor-patient relationship (Ghadirian, "Spiritual Dimension"). In the nineteenth century, Canadian physician Sir William Osler stated, "Nothing in life is more wonderful than faith-the one great moving force which we can neither weigh in the balance nor test in the crucible ... Faith has always been an essential factor in the practice of medicine" (1470). Less than sixty years ago, Carl G. Jung, in a letter to Dr. Bill Wilson, one of the co-founders of AA, wrote about the relationship between spirituality and substance abuse: "You see, alcohol in Latin is spiritus and you use the same word for the highest religious experience as well as the most depraving poison. The helpful formula therefore is: spiritus contra spiritum." From a biblical perspective, the ancient epithet spiritus contra spiritum means that spirits (alcohol) or drugs can drive out spirituality; on the other hand, spirituality may play a protective role, preventing alcohol and psychoactive drugs from prevailing (Miller 980).

Religion provides a sense of meaning in life, and religious involvement serves as a protection against substance abuse disorders. Interestingly, the word "religion" comes from the Latin religare, which means "to bind together." In their paper on religiosity's implications for the practice of medicine, Mueller, Plevak, and Rummans note how "most studies have shown that religious involvement and spirituality are associated with better health outcomes, including greater longevity, coping skills, and health-related quality of life ... [S $]$ everal studies have shown that addressing the spiritual needs of the patient may enhance recovery from illness" (1225). Furthermore, they state that "throughout history, religion and spirituality and the practice of medicine have been intertwined. As a result, many religions embrace caring for the sick as a primary mission” (1225).

A large number of research studies and literature reviews have confirmed 
that religious beliefs and practices relate to health and healing (e.g., Koenig, "Religion, Spirituality, and Health"; Miller; Bou-Yong). In one such study, the possible relationship between religious affiliation and alcoholism among medical professionals was examined from 1948 to 1964 among 1,337 medical students at Johns Hopkins University. In 1986, a follow-up study regarding consumption of alcohol was done with these same students, who were by then graduated physicians. Results showed that a lack of affiliation with religion during medical school was a strong predictor of future alcohol problems (Moore et al.). According to a review of research prior to 2000 about the relationship between religiosity and alcohol problems, which evaluated eighty-six research studies, seventy-six found a positive correlation between religiousness and lower alcohol intake, abuse, and dependence (Koenig, Medicine 60). In a 2001 study, adults who did not consider religion to be important were three times more likely to binge drink (60). Koenig and his collaborators also found indications that a positive correlation exists between religion and prevention of substance abuse. They noted that of the 175 studies reviewed, 147 suggested that religious beliefs might be a deterrent to the use of alcohol and drugs by children, adolescents, and adults (Handbook).

Whereas a material treatment modality meant to remedy a detectable physical deficiency contributing to drug addiction may be easily tested and measured, spirituality, an intangible phenomenon, cannot be; yet, it may have a protective influence by counteracting the temptation to engage in behaviors that would lead to addiction. As shown in the studies above, lack of religious affiliation and involvement seems to be more often observed among alcoholics and drug addicts. Another relevant observation is that women who are partners of alcoholic men are reportedly much less religious in their attitude and behavior (Miller). Over eighty percent of one hundred studies on religion and alcohol consumption problems imply that there is less incidence of alcoholism for those with religious affiliation or belief (Koenig, Handbook). Nevertheless, further study is required to determine whether religion and spirituality are a definitive protective determinant against addiction.

\section{Spirituality as a Mediator or Catalyst}

Understanding the dynamics of the influence of the soul and spirituality on healing and recovery from any disease, including addiction, is challenging, partly because contemporary research methodology is unsuited for such an exploration. Such methodology is unable to translate the mystical and intangible influence of religious values and spiritual practices such as love, empathy, compassion, and justice into tangible physical measurements and statistics. Although researchers have formulated questionnaires that 
attempt to measure religiosity or spiritual values, those measurements are expressed, for example, as changes in heart rate and blood pressure, which are markers of relaxation during prayer and meditation. However, these measurements fail to explain the mechanism of how prayer or worship results in action through brain function and neurotransmitters-that is, how spiritual power interacts with millions of brain cells to bring about certain actions or behaviors that the present authors assume to originate from the soul. Moreover, the scientific community does not attempt to explain what the soul and spirituality are, especially since science itself does not readily accept the existence of metaphysical reality, let alone the existence of the soul as an essential part of human existence.

The present authors accept that there is a spiritual reality and that the soul itself is a metaphysical essence; due to this non-physicality, the soul and its relationship to human wellbeing are not measurable through current scientific technology. For this reason, although there are many theories about the influence of spiritual and religious practice and affiliation on treating and preventing drug abuse and addiction, it is not easy to prove them.

Nevertheless, spirituality may support the recovery process. The period of recovery from drug addiction, especially in the beginning, can be very sensitive and perhaps stressful because, after being repeatedly influenced by addictive drugs for a long time, the faculties of the brain need to restore their normal activities. During this process of healing and severance from the use of addictive drugs, there may be a sense of panic. A recovering alcoholic might say: "I'm sober. Now what do I do?” (White and Laudet 59). The feeling is comparable to the sentiment experienced upon returning home after a long and troubled journey only to find that home no longer seems familiar. In this period of transition, spirituality may provide a new framework of understanding based on personal values and beliefs.

An hypothesis that describes spirituality as a mediator or catalyst in recovery from substance abuse was proposed by White and Laudet in their review of studies on the role of spirituality in recovery from addiction. They concluded that " $[\mathrm{s}]$ pirituality can be a catalyst of recovery initiation, a protective shield in early recovery and an increasingly significant dimension of long-term recovery maintenance" and that the role of spirituality in recovery initiation was very remarkable (58). They also found that this catalyst was often activated at a "turning point" such as a near-death experience due to an overdose, a suicide attempt, or the addiction-related death of a close friend.

\section{Some Possible Mechanisms of} Spirituality's EFfect on AdDiction There are some research studies which suggest that meditation, when used as 
a spiritual practice, has a beneficial effect on mental health. One such study states, "[t] he exact neural basis of these effects is slowly coming to light and different imaging techniques have elucidated the neural basis of meditative practices. The evidence though preliminary ... points toward the involvement of the prefrontal and parietal cortices. The available data on meditation focus on activated frontal attentional network" (Mohandas 63). This study shows that the neurobiological results of meditation have positive effects on mental health, implying that meditation as a spiritual practice might have a protective effect against the craving that may lead to substance abuse and addiction. Anxiety, depressive symptoms, and loss of hope and a sense of meaning in life are but some of the psychological experiences that may lead to substance abuse and addiction. Meditation, mindfulness, reliance on faith, and religious beliefs and practices seem to provide a buffer against the tendency toward seeking some temporary and artificial solution, such as illicit drugs.

Spiritual practices such as meditation and prayer can also be a means for enhancing cognition, communication, and creativity, and may even change our perception of reality (Newberg and Waldman 7). Furthermore, spiritual practices reportedly have an effect on the neurotransmitters (chemical messengers released by nerve cells or neurons) of the brain and body. As an example, researchers found a sixty-five percent increase in dopamine in individuals who practice yoga ni$d r a .^{2}$ It is noted that during meditation there is an increase in the release of dopamine in the brain. This increase is associated with heightened conscious, sensory or imagery perception, and a relaxed and positive experience (Kjaer et al. 257 and 259). However, besides the neuropsychological effects of spirituality on substance abuse, religious teachings and exhortations can also have significant influence on behavior and perception with respect to illicit drug use.

To summarize, the following pragmatic hypotheses may be helpful in understanding the relationship between spirituality and drug addiction:

Religion and spirituality enhance psychological and, likely, physical aspects of wellbeing. For example, in some parts of the world where the consumption of alcohol is strictly forbidden by religion, there is low prevalence of alcoholism and its adverse consequences. The same applies to the non-medical use of psychoactive drugs such as LSD, cocaine, and opioids (Koenig, Medicine, Religion and Health 58-59).

Spiritual beliefs provide a sense of hope, social support, and coping mechanisms in dealing with hardships and

2 Also known as "yogic sleep," yoga nidra is considered to be an extremely relaxed state of consciousness such as that experienced at the transition between wakefulness and sleep. 
life crises, as exemplified by the AA Twelve-Step program, which is based on spirituality and encourages perseverance in abstaining from the use of alcohol.

Spirituality may act as a mediator that empowers individuals to move from being captivated by drug use to being liberated from it. It is important to note that such a transformation depends on faith, the nature of which the human mind is unable to fathom, as well as on individual will.

\section{Methodological Challenges}

Exploring the effect of spirituality on substance abuse disorders and their treatment is fraught with challenges, as several factors can affect the outcome of such studies:

A lack of a universally agreed-upon definition of spirituality and even religiosity among researchers.

A lack of standard evaluation and measurement tools for assessing the effect of spiritual and religious values-although some scales and questionnaires have been developed to measure spirituality based on frequency of worship, attendance at religious services, and other religious practices (Baetz et al.).

The inability of current scientific research to quantify intrinsic and spiritual values.

In brief, methodological problems will continue as long as research in this field remains constrained by measurements based exclusively on material or phenomenal exploration.

\section{A Bahá'í Perspective on Addiction}

The Bahá'í Writings are very explicit with regard to the non-medical use of drugs. Bahá'ís should abstain from all forms of intoxicants, such as alcohol, drugs, and "hallucinogenic agents, including LSD, peyote and similar substances" (Universal House of Justice, qtd. in Hornby 354). On the other hand, it is important to know that the Bahá'í Faith recognizes the medicinal benefits and therapeutic effects of some of these substances. The use of these drugs is permissible when they are prescribed by a physician; however, recreational drug use is prohibited because it can seriously impair the human brain and mind.

Of course, as mentioned above, it is important to give attention to both the material and the spiritual aspects of treatment-to pair assistance from the medical profession with whatever spiritual methods one might choose to employ. From a Bahá'í point of view, the idea that spirituality has an effect on addiction recovery and prevention stems from the belief that human beings are created noble and are essentially spiritual beings. In fact, the Bahá'í Writings tell us that mental faculties are properties of the soul expressed through the instrumentality of the brain ('Abdu'l-Bahá, Paris Talks 83-84; see also His “Tablet to Auguste Forel”). As such, the brain plays a very important role because, as 'Abdu'l-Bahá explains, the reality of a human being is his thought and intellect (4). Because the brain mediates 
between the soul and human thought and intellect, mental functioning and behavioral patterns will be adversely affected by inappropriately used drugs that excessively stimulate or suppress healthy brain activity, especially when such abuse occurs repeatedly or over an extended period.

'Abdu'l-Bahá elucidates the role and significance of the spirit and the rational soul in the following observation:

The human spirit, which distinguishes man from the animal, is the rational soul, and these two terms - the human spirit and the rational soul-designate one and the same thing. This spirit, which in the terminology of the philosophers is called the rational soul, encompasses all things and, as far as human capacity permits, discovers the realities and becomes aware of the properties and effects, the characteristics and conditions of earthly things.

As for the mind, it is the power of the human spirit. The spirit is as the lamp, and the mind as the light that shines from it. (Some Answered Questions 55:2-3)

The soul or spirit is a non-material essence independent of the body; yet, when its instrumentality in directing the body is encumbered or damaged, its ability to become edified by physical experience would presumably be severely compromised. At the same time, an analogy in the Bahá'í Writings explains that bodily or mental infirmity has no effect on the soul by comparing bodily illness or incapacity to a cloud that interposes itself between the sun (the soul) and the earth (the body). Just as the sun continues to shine even though its rays may not be visible because of the cloud, the soul is ever present, even though it may be hidden by the effects of the infirmity:

Know thou that the soul of man is exalted above, and is independent of all infirmities of body or mind. That a sick person showeth signs of weakness is due to the hindrances that interpose themselves between his soul and his body, for the soul itself remaineth unaffected by any bodily ailments. (Bahá'u'lláh, Gleanings 80:2).

The spiritual practice of meditation mentioned above is also highly valued in the Bahá'í Writings. 'Abdu’l-Bahá states, "The spirit of man is itself informed and strengthened during meditation ... Meditation is the key for opening the doors of mysteries" (Paris Talks 187). Furthermore, He explains that the "faculty of meditation frees man from the animal nature, discerns the reality of things, [and] puts man in touch with God. This faculty brings forth from the invisible plane the sciences and arts" (188).

The following insightful comment seems to imply that through our willpower we can use the power of meditation for good or ill, depending on 
whether we focus on elevated or base interests:

The meditative faculty is akin to the mirror; if you put it before earthly objects it will reflect them. Therefore if the spirit of man is contemplating earthly subjects he will be informed of these. But if you turn the mirror of your spirits heavenward, the heavenly constellations and the rays of the Sun of Reality will be reflected in your hearts, and the virtues of the Kingdom will be obtained. Therefore let us keep this faculty rightly directed-turning to the heavenly Sun and not to earthly objects. ('Abdu'l-Bahá, Paris Talks 188)

Applying the above analogy to the subject at hand, it would seem that to fix one's attention on an addictive substance would be like turning one's mirror toward an earthly object. By shifting one's concentration toward more positive ideals, freedom from attachment to addictive substances might be achieved. Moreover, such reflection gives a deeper meaning to the purpose of life and our spiritual destiny, a process which can be quite liberating.

One of the most common feelings among those who are attracted to alcohol and other drugs, especially in a world where love and empathy may be hard to find, is the loss of self-confidence. Having faith, mindfulness, and spiritual understanding of the purpose of life gives one a deeper perspective on life and its meaning, and thus can naturally be very reassuring. Bahá'u'lláh reminds us about our nature and purpose with these emphatic words: "Thou art My dominion and My dominion perisheth not; wherefore fearest thou thy perishing?" (Arabic Hidden Words no. 14).

\section{Further Reflections on the Prevention of Substance Abuse}

Modern scientific advancements and unprecedented medical discoveries have not been able to mitigate or prevent the rising consumption and abuse of mind-altering and addictive substances. 'Abdu'l-Bahá explains that " $[\mathrm{u}]$ nless the moral character of a nation is educated, as well as its brain and its talents, civilization has no sure basis" (Paris Talks 21 ). In response to this warning, what approach might society take? A sound and appropriate path might include an ongoing preventive educational program that would provide a healthy and protective approach to the eradication of substance abuse.

Easy availability of narcotics and mind-altering drugs may seem enticing; however, a progressive society will take into consideration the vital importance of protecting the minds of the future generation through preventing alcohol and drug abuse. Neurologist and psychiatrist Viktor Frankl in his book The Doctor and the Soul expresses an insightful view on people's indulgence in illicit drugs. He criticizes the recreational use of these substances, believing that the 
consumption of narcotics and "narcotization" is, effectively, a "spiritual anaesthesia" that can lead to spiritual death. He moreover asserts that "consistent suppression of intrinsically meaningful emotional impulses" can destroy a person's inner life (88-89).

Furthermore, while consumption and overuse of analgesics and tranquilizers temporarily gratify our physical and emotional needs, their long-term and non-prescribed use can interfere with the ability to deal with life's challenges. When psychological stress is constantly suppressed without any insight into its meaning gained, we lose an opportunity for personal growth. As Frankl comments, "man's main concern is not to gain pleasure or to avoid pain, but rather to see a meaning in life" (Man's Search for Meaning 179). This, however, does not mean that people should avoid analgesics; rather, they should use them moderately and wisely as they follow medical advice.

An unfortunate impediment in the treatment of substance abuse, which must be overcome, is treatment avoidance due to the perceived shame and stigma attached to this illness. One of the remarkable effects of religion and spirituality is their capacity to cultivate a sense of social support and to nurture caring relationships with those who are sick and suffering. Such support and relationships will not only reduce the stigma and shame, but will also provide a therapeutic as well as a spiritual community characterized by greater caring and acceptance. Indeed, a caring, compassionate, and supportive community can contribute to the healing process of these patients, who face great emotional challenges in their lives.

\section{Conclusion}

In May 2017, at the annual conference of the American Psychiatric Association, one of the highlights was a special convocation in which a world-renowned journalist and recovered alcoholic, Elizabeth Vargas, spoke about her addiction ("Highlights"). Vargas acknowledged that one of the important elements of her long and arduous journey to recovery was her faith and spiritual perspective, which allowed her to carry treatment to a successful conclusion. This was a courageous admission before thousands of psychiatrists, many of whom might have been less inclined to share this belief.

Most researchers and clinicians believe that alcoholism is a disease of the brain and treat patients according to the medical model. While medical treatment of addiction is important, we should not underestimate the significance of whole-person care, the role of the soul, and the spiritual needs of the patient, something which unfortunately happens quite often.

The rise of substance abuse disorders and addiction around the world reflects an existential crisis of humanity, which involves not only adults from all walks of life, but also teenagers and children. To counter this crisis, 
large-scale comprehensive programs of preventive education, regulation of narcotics and illicit drugs, and more effective harm-reduction policies and programs against all forms of illegal drugs, as well as positive alternatives, need to be put in place (Ghadirian, $\mathrm{Al}$ cohol and Drugs).

In summary, drug addiction is a global public health crisis affecting millions of people with an astronomical human, economic, and societal cost. There is no single cause and hence no simple solution. This crisis affects all strata of society; it is our collective problem, and it requires a collective solution. Society needs to find innovative ways to solve the problem and to realize that enforcing a solution through legislation will not work by itself. Only a root-cause approach that will change the social environment, protecting people from such a lifelong afflictive disorder, will have a lasting effect.

Research shows that spirituality and religious values have a positive effect and can contribute to public education for substance abuse prevention. Moreover, emerging findings suggest that religious and spiritual practices, including meditation, may have a positive influence on the brain and on human behavior, and thus may contribute to the prevention of, as well as to the recovery from, drug abuse and addiction. Nevertheless, the mechanism whereby an intangible phenomenon such as spirituality or religion influences these processes remains an enigma. This article attempts to unravel some challenging aspects of this enigma. Indeed, the well-documented results of the twelve steps of AA since the 1930 s are a pragmatic testimony that religiosity and spirituality do have positive effects on the preventive and healing processes in drug addiction. This is not to claim that they replace medical and psychosocial efforts in remedying the affliction. Rather, applying religious and spiritual values in the process complements using scientific advances in curbing this widespread crisis of humanity.

\section{Works Cited}

'Abdu'l-Bahá. Paris Talks. Addresses Given by 'Abdu'l-Bahá in Paris in 1911-1912. UK Bahá'í Publishing Trust, 1995.

- Some Answered Questions. Bahá'í World Centre, 2014.

- "Tablet to Auguste Forel." The Bahâ'i World, vol. 15, Bahá'í World Centre, 1921 , pp. 37-43.

Baetz, Marilyn, et al. "The Association between Spiritual and Religious Involvement and Depressive Symptoms in a Canadian Population." Journal of Nervous and Mental Disease, vol. 192, no. 12, 2004, pp. 818-22.

Baháu'lláh. Gleanings from the Writings of Bahá'u'lláh. Translated by Shoghi Effendi, US Bahá'í Publishing Trust, 1994. 
The Hidden Words of Baháu'lláh. US Bahá'i Publishing Trust, 2003.

Bergland, Christopher. "The Neurochemicals of Happiness." Psychology Today, 29 Nov. 2012, www.psychologytoday.com/ca/blog/the-athletesway/201211/the-neurochemicals-happiness.

Blake, Joann. "Dangerous' Alcohol Consumption on the Rise in the U.S.” Psychiatric Neres, 12 Sep. 2017, doi.org/10.1176/appi.pn.2017.9b5.

Bou-Yong, Rhi. "Culture, Spirituality and Mental Health: The Forgotten Aspects of Religion and Health." Psychiatric Clinic of North America, vol. 24, no. 3, 2001, pp. 569-79.

"Drug Overdoses Now Kill More Americans than Guns." CBS Neres, 9 Sep. 2016, www.cbsnews.com/news/drug-overdose-deaths-heroin-opioid-prescription-painkillers-more-than-guns/.

Frankl, Viktor. Man's Search for Meaning: Pocket Books, 1975.

- The Doctor and the Soul. Bantam Books, 1967.

Gagnon, Louise. "Reports Suggest Physicians Over-Prescribed Opioids." Chronicle of Neurology \& Psychiatry (December, 2014). issuu.com/ thechronicleofneurologypsychiatry/docs/52035_n_p_dec_2014_ei_rar_ms.

Ghadirian, Abdu'l-Missagh. Alcohol and Drug Abuse: A Psychosocial and Spiritual Approach to Prevention. George Ronald Publisher, 2007.

_ . "Spiritual Dimensions of Whole Person Care." Whole Person Care: A New Paradigm for the $21^{\text {st }}$ Century, edited by Tom A. Hutchinson, Springer, 2011, pp. 149-60.

Hatcher, William S. “The Concept of Spirituality.” Bahâ'i Studies, vol.1 1, Association for Bahá'í Studies, 1982.

"Highlights from the 2017 National Psychiatric Convocation: ABC Journalist Shares Story of Strength and Inspiration." Medworks Media, 24 May 2017, medworksmedia.com/highlights-2017-national-psychiatricconvocation/.

Hill, Peter C. and Kenneth I. Pargament. "Advances in the Conceptualization of Measurement of Religion and Spirituality." American Psychologist, vol. 58, no. 1, 2003, pp. 64-74.

Hornby, Helen Basset, editor. Lights of Guidance: A Bahá'i Reference File. India Bahá’í Publishing Trust, 1999.

Jarusiewicz, Betty. "Spirituality and Addiction: Relationship to Recovery and Relapse." Alcoholism Treatment Quarterly, vol. 18, no. 4, 2000, pp. 99-109.

Kissman, Kris and Lynn Maurer. "East Meets West: Therapeutic Aspects of Spirituality in Health, Mental Health and Addiction Recovery." International Social Work, vol. 45, no. 1, 2002, pp. 35-43.

Kjaer, Troels W., et al. "Increased Dopamine Tone During Meditation-Induced Change of Consciousness." Brain Research, Cognitive Brain Research, vol. 13, no. 2, 2002, pp. 255-59. 
Koenig, Harold G. Medicine, Religion and Health. Templeton Foundation Press, 2008.

- "Religion, Spirituality, and Health: A Review and Update." Advances in Mind-Body Medicine, vol. 29 no. 3, 2015, pp. 19-26.

"Religion, Spirituality, and Health: The Research and Clinical Implications.” ISRN Psychiatry, vol. 2012, dx.doi.org/10.5402/2012/278730.

Koenig, Harold G., Michael E. McCullough, and David B. Larson. Handbook of Religion and Health. Oxford UP, 2001.

Laudet, Alexandre and William White. "The Role of Spirituality, Faith and Life Meaning in the Addiction Recovery Process." $28^{\text {th }}$ Congress of the World Federation for Mental Health, 10-15 Sep. 2005, Cairo, Egypt. Conference Presentation.

Levin, Aaron. "Tackling Opioid Overdose Epidemic Demands Multiple Approaches.” Psychiatric News, 30 Jun. 2017, doi.org/10.1176/appi.pn.2017.7a6.

Mattoo, S.K., et al. "Prevalence and Correlates of Epileptic Seizure in Substance-Abuse Subject.” Psychiatry and Clinical Neurosciences, vol. 63, no. 4, 2009, doi.org/10.1111/j.1440-1819.2009.01980.x.

"Mental Disorders Affect One in Four People." World Health Organization, 4 Oct. 2001, www.who.int/whr/2001/media_centre/press_release/en/.

Miller, William R. "Researching the Spiritual Dimensions of Alcohol and Other Drug Problems.” Addiction, vol. 93, no. 7, 1998, pp. 979-90.

Mohandas, E. "Neurobiology of Spirituality." MSM: Mens Sana Monograph, vol. 6, no. 1, 2008, pp. 63-80.

Moore, Richard D., Lucy Mead, and Thomas A. Pearson. "Youthful Precursors of Alcohol Abuse in Physicians.” The American Journal of Medicine, vol. 88, no. 4, 1990, pp. 332-36.

Mueller, Paul S., David J. Plevak, and Teresa A. Rummans. "Religious Involvement, Spirituality, and Medicine: Implications for Clinical Practice.” Mayo Clinic Proceeding, vol. 76, no. 12, 2001, pp. 1225-35.

"Risk and Protective Factors in Drug Abuse Prevention." National Institute on Drug Abuse. archives.drugabuse.gov/news-events/nida-notes/2002/02/ risk-protective-factors-in-drug-abuse-prevention.

Neff, James A. and Samuel A. MacMaster. "Spiritual Mechanisms Underlying Substance Abuse Behavior." Journal of Social Work Practice in the Addictions, vol. 5, no. 3, 2005, pp. 33-54.

Newberg, Andrew and Mark Robert Waldman. How God Changes Your Brain. Ballantine Books, 2009.

Osler, William. "The Faith that Heals." The British Medical Journal, 1910, pp. 1470-72.

"Prescription Drug Abuse." National Institute on Drug Abuse, Oct. 2011, www. drugabuse.gov/sites/default/files/rxreportfinalprint.pdf. 
Project MATCH Research Group. "Matching Alcoholism Treatments to Client Heterogeneity: Project MATCH Post-Treatment Drinking Outcomes.” Journal of Studies on Alcohol, vol. 58, no. 1, 1997, pp. 7-29.

Seelye, Katharine Q. “A Mother Lifts Her Son, Slowly, from Heroin’s Abyss.” New Tork Times, 10 Aug. 2014. www.nytimes.com/2014/08/11/us/a-motherlifts-her-son-slowly-from-heroins-abyss.html.

“Substance Abuse.” World Health Organization, www.who.int/topics/substance_ abuse/en. Accessed 22 Jan. 2019.

Tigunait, Pandit Rajmani. The Inner Quest: Yoga's Answers to Life's Questions. Himalayan Institute Press, 2002.

“Provisional Counts of Drug Overdose Deaths, as of 8/6/2017." United States Centers for Disease Control and Prevention. www.cdc.gov/nchs/data/ health_policy/monthly-drug-overdose-death-estimates.pdf.

Volkow, Nora D. “America's Addiction to Opioids: Heroin and Prescription Drug Abuse-Witness Appearing before the Senate Caucus on International Narcotics Control.” National Institutes of Health, 14 May 2014, www.nih. gov/sites/default/files/institutes/olpa/20140514-senate-testimonyvolkow.pdf.

White, William and Alexandre Laudet. "Spirituality, Science and Addiction Counseling.” Counselor Magazine, vol. 7, no. 1, 2006, pp. 56-59.

“World Drug Report 2018." United Nations Office on Drugs and Crime. www. unodc.org/wdr2018/. 